\title{
Not so bad ... but not as good as we would like
}

\author{
Robert D. B. Jaquiss, MD
}

From the Department of Cardiothoracic Surgery, Duke University School of Medicine, Durham, NC.

Disclosures: Author has nothing to disclose with regard to commercial support.

Received for publication June 21, 2015; accepted for publication June 23, 2015; available ahead of print July 22, 2015.

Address for reprints: Robert D. B. Jaquiss, MD, Department of Cardiothoracic Surgery, Duke University School of Medicine, DUMC 3474, Durham, NC 27710 (E-mail: robert.jaquiss@ duke.edu).

J Thorac Cardiovasc Surg 2015;150:1463-4

$0022-5223 / \$ 36.00$

Copyright $(2015$ by The American Association for Thoracic Surgery

http://dx.doi.org/10.1016/j.jtcvs.2015.06.058

In the past 75 years, surgical treatments have been developed for patients with virtually any type of congenital cardiac malformation. When these solutions are incompletely effective or inadequately durable, heart transplantation is required. The present report, describing a 25-year experience at a large children's hospital, reminds us of both the effectiveness and shortcomings of this "bail-out" therapy. ${ }^{1}$ Many lessons are already well known: Transplantation for congenital heart disease is less successful than it is for cardiomyopathy; younger patients do better than older patients; and retransplantation is significantly riskier than initial transplantation. Some insights gleaned from this work were more surprising, and in 1 case, disappointing, at least to the investigators.

The authors described as discouraging the finding that posttransplant survival outcomes did not improve over the study period. They had presumably hypothesized that improved medical care and immunosuppression would produce better outcomes. To test this hypothesis, they dichotomized their cohort at the year 2000, and found no improvement in early or late survival over time. Although their distress at unimproved survival is understandable, in the latter period, recipients were much more ill $(89 \%$ were United Network for Organ Sharing status I in the later era, vs $49 \%$ status I in the earlier era). Furthermore, bypass times were longer by nearly 30 minutes in the later era, implying more-complex transplant operations. Perhaps most importantly, ischemic times were $>30$ minutes longer in the later period. Considering these between-era differences, an alternative, less "discouraging," interpretation is that excellent outcomes were maintained despite the trend toward transplantation in sicker patients, who were undergoing more-complex transplants, with longer ischemic times.

An unequivocally encouraging finding was the remarkably outstanding outcomes in Fontan patients, a subgroup that has been found in several studies to be at particularly high risk for early mortality. ${ }^{2,3}$ To the contrary, the results reported here describe only 1 operative death in 33 patients, an astonishingly excellent result, comparable to outcomes for children who receive transplants to treat

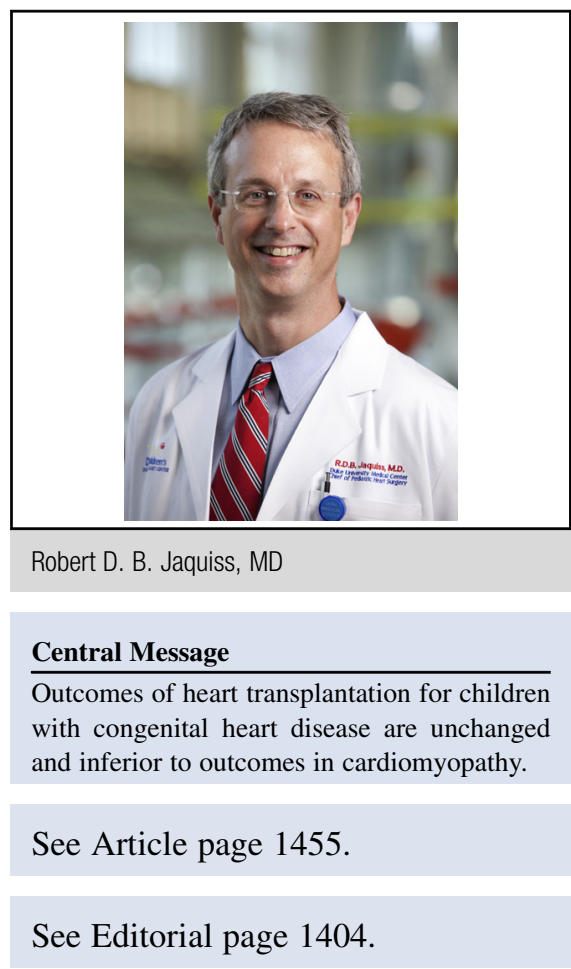

cardiomyopathy. The explanation for these superior results is not immediately clear from the article, although they do provide a clear opportunity for other centers to learn from the Atlanta approach. Given the large number of patients who now survive multistage palliation, particularly those with hypoplastic left heart syndrome and its variants, the cohort of post-Fontan patients is likely to increase in size significantly over the next decades. Many or most in this group will require transplantation at some point, and this report provides a performance standard to be emulated for those patients.

A more sobering finding is that African-American pediatric heart transplant recipients have lower survival after transplantation, as the authors had previously found. ${ }^{4,5}$ Additionally, donor-recipient mismatch was a risk factor for worse late outcomes in both white and AfricanAmerican recipients. A recent study evaluating the influence of race in adult transplant recipients demonstrated similar findings, although donor-recipient mismatch was not a risk factor for African-American recipients. ${ }^{6}$

At present, a complete mechanistic explanation remains elusive, not least because of the lack of a biologic definition of race. As has been repeatedly pointed out, there is only 1 race. Furthermore, the potential implications of any 
discussion in this area are fraught with controversy, as was well discussed in a recent editorial. ${ }^{7}$ Whether or how these and similar results will influence the practice of heart transplantation requires thoughtful and extensive investigation and discussion.

Two additional and related aspects of this report are waitlist mortality and mechanical bridge to transplant. Although these topics are mentioned briefly, the patients who died before they could receive a transplant $(21 \%$ of those listed during the study period) provide mute testimony to the lack of timely access to suitable donors. The point has been made before, but it bears repeating: waitlist mortality among children has been and remains unacceptably high. A relatively new, partial solution to this problem-durable mechanical circulatory support—had not yet materialized during most of the study period.

A striking aspect in this report is that no patient was supported by a ventricular assist device (VAD), and only a small number $(5 \%)$ were put on extracorporeal membrane oxygenation support. This fact is an unfortunate and unavoidable weakness of this report, given the recent introduction of VADs for pediatric heart transplant candidates. At present, at least $30 \%$ of pediatric heart transplant recipients will be supported by VAD, and although VAD usage is much more common among cardiomyopathy patients, its application to patients who have congenital heart disease is increasing rapidly.

For all its successes, congenital heart surgery has long been known to not be curative in the vast majority of patients. This report will help guide us in caring for those for whom an alternative solution is necessary.

\section{References}

1. Alsoufi B, et al. Outcomes and risk factors for heart transplantation in children with congenital heart disease. J Thorac Cardiovasc Surg. 2015;150:1455-62.e1-3.

2. Bernstein D, Naftel D, Chin C, Addonizio LJ, Gamberg P, Blume ED, et al. Outcome of listing for cardiac transplantation for failed Fontan: a multiinstitutional study. Circulation. 2006;114:273-80.

3. Davies RR, Sorabella RA, Yang J, Mosca RS, Chen JM, Quaegebeur JM. Outcomes after transplantation for "failed" Fontan: a single-institution experience. J Thorac Cardiovasc Surg. 2012;143:1183-92.

4. Mahle WT, Kanter KR, Vincent RN. Disparities in outcome for black patients after pediatric heart transplantation. J Pediatr. 2005;147:739-43.

5. Kanter KR, Berg AM, Mahle WT, Vincent RN, Kilgo PD, Kogon BE, et al. Donorrecipient race mismatch and graft survival after pediatric heart transplantation. Ann Thorac Surg. 2009;87:204-9.

6. Kilic A, Higgins RS, Whitson BA, Kilic A. Racial disparities in outcomes of adult heart transplantation. Circulation. 2015;131:882-9.

7. Taylor AL. Racial differences and racial disparities: The distinction matters. Circulation. 2015;131:848-50. 